\title{
sciendo
}

\section{The Relative Age Effect on Anthropometry, Body Composition, Biological Maturation and Motor Performance in Young Brazilian Soccer Players}

\author{
by \\ Juliana Melo Altimari ${ }^{1}$, Leandro Ricardo Altimari ${ }^{1}$, Henrique Bortolotti ${ }^{1}$, \\ Adalberto Ferreira Junior', Juliano Moro Gabardo, Cosme Franklim Buzzachera ${ }^{1,2}$, \\ Ariobaldo Frisselli ${ }^{1}$, Antonio Carlos de Moraes ${ }^{1,3}$
}

\begin{abstract}
The present study aimed to investigate the influence of months of birth on anthropometry, body composition, biological maturation, and motor performance in young Brazilian soccer players. Young Brazilian soccer players from the Under-13 ( $n=50 ; 13.6 \pm 0.3$ years), Under-15 ( $n=50 ; 15.5 \pm 0.4$ years), and Under-17 categories $(n=46 ; 17.7 \pm$ 0.3 years) took part in this study. Athletes were divided according to chronological age, $1^{\text {st }}$ tertile (January to April); $2^{\text {nd }}$ tertile (May to August); and 3 $3^{\text {rd }}$ tertile (September to December). Anthropometry, body composition, biological maturation, and motor performance variables were evaluated for all participants. There were no differences between the $U-13, U-15$, and $U-17$ categories regarding birth tertiles $(p>0.05)$. Differences between the ages and birth tertiles were observed for the stature, body mass, and lean body mass $(p<0.05)$. Moreover, differences were found in maturational status between the ages and birth tertiles $(p<0.05)$. In general, $U-13$ players showed lower values compared to U-15 and U-17 players in tests of motor performance. In addition, there was a difference in motor performance between the birth tertiles only for RSA variables. The months of birth influenced the stature, body mass, lean body mass, and repeated sprint ability in the $U-13$ and $U-15$ categories. Thus, care should be taken during the process of talent selection, as many young players could be underestimated due to their date of birth.
\end{abstract}

Key words: birth date, fatigue, maturation, sport, young athletes.

\section{Introduction}

The process of talent identification may have a decisive influence in sports. In soccer, the selection of youth males and females may be related to early physical maturation, and this could influence some physiological variables (Figueiredo et al., 2009; Gil et al., 2014; Gravina et al., 2008; Sedano et al., 2015; Wong et al., 2009). Additionally, it has been demonstrated that young people with accelerated maturational stages present advantages in sports performance
(Duarte et al., 2019; Figueiredo et al., 2009; Gil et al., 2014; Práxedes et al., 2017; Wong et al., 2009).

The majority of countries select the birth year as a criterion for grouping of competitive categories, adopting the rules of the International Federation of Associated Football (FIFA) (Helsen et al., 2005). Thus, young people born in the first months of the calendar seem to benefit, as they present greater chronological age and, consequently, are more likely to be in more advanced stages of biological maturation

\footnotetext{
1 - Group of Study and Research in Neuromuscular System and Exercise, Physical Education and Sport Center - State University of Londrina, Londrina, Paraná, Brazil.

2 - Department of Public Health, Experimental and Forensic Medicine, University of Pavia, Pavia, Italy.

3 - State University of Campinas. School of Physical Education. Campinas, Brazil.
} 
(Altimari et al., 2018, 2011; Costa et al., 2012; Duarte et al., 2019). Various studies have demonstrated the advantages in physical abilities, cognitive knowledge, and psychological capacity in individuals with a greater chronological age (Cobley et al., 2009; Delorme et al., 2013; Malina et al., 2007; Sherar et al., 2007; Vincent and Glamser, 2006). Furthermore, it has been shown that the month of birth exerts influence on differences in body size (Carling et al., 2009; Duarte et al., 2019).

Therefore, early maturing players are favored in the process of selection (Carling et al., 2009; González-Víllora et al., 2015; Hirose, 2009). This phenomenon has been called relative age effect (RAE) in the literature, and is observed in some sports (Carling et al., 2009; Cobley et al., 2009; Delorme et al., 2013; Hirose, 2009; López de Subijana and Lorenzo, 2018; Musch and Grondin, 2001; Wrang et al., 2018). In addition, RAE is present in the selection of Brazilian players with progressive growth over the last decades (Altimari et al., 2018, 2011; Costa et al., 2012).

Although studies have analyzed the relationship between the month of birth and body structures (e.g. body mass and stature), few have analyzed the influence of months of birth on motor skills, power, and endurance performance. Furthermore, no studies have investigated how muscle fatigue can be influenced by months of birth. Thus, the objective of this study was to analyze the influence of months of birth on anthropometric, body composition, biological maturation, and motor performance in young Brazilian soccer players.

\section{Methods}

\section{Participants}

Initially, the sample size was calculated from the stature variable presented in the study by Carling et al. (2009) considering a statistical power of $80 \%$ and an alpha error of 0.05 , which indicated the need for between 45 and 51 athletes per category, distributed between 15 and 17 athletes separated according to the categorization of chronological age in four-month periods. Thus, the sample was composed of 146 young Brazilian soccer players from the Under-13 $(\mathrm{U}-13, \mathrm{n}=50$; $13.6 \pm 0.3$ years), Under- 15 ( $U-15, n=50 ; 15.5 \pm 0.4$ years), and Under-17 categories (U-17, $\mathrm{n}=46 ; 17.7$ \pm 0.3 years) who were evaluated over a period of three years. Athletes had been involved in a soccer training program for more than 6 years, with participation in regional and state competitions, and at least four training sessions per week, in addition to official competitive games on weekends. The evaluations were carried out at the beginning of the preparation phase of the annual training cycle. All parents of the participants were aware of the procedures and risks of the experimental protocol and signed an informed consent form. This study was approved by the local Ethics Research Committee in accordance with the Declaration of Helsinki (CAAE: 25223313.0.0000.5231).

Determination of the tertiles according to the months of birth

Soccer players were divided according to categorization of chronological age, i.e., birth date, every four months, $1^{\text {st }}$ tertile ( $\left.1^{\text {st }} \mathrm{TR}\right)$, players born between January and April; $2^{\text {nd }}$ tertile ( 2 nd $T R$ ), born between May and August, and $3^{\text {rd }}$ tertile ( $3{ }^{\text {rd }}$ TR), born between September and December. Initially, participants were submitted to anthropometric evaluation (stature and body mass) and skinfold thickness measurements to estimate body composition. In the following session, motor tests were applied. Participants were previously submitted to the tests used for familiarization with the test protocols and equipment. Subsequently, radiographs of the wrist region were taken to evaluate bone maturation.

\section{Anthropometry and body composition}

Body mass was measured on a PS $180^{\circledR}$ (Urano $^{\mathrm{TM}}$, Brazil), and the stature was determined using a Standard Sanny ${ }^{\circledR}$ (Sanny $^{\mathrm{TM}}$, Brazil) aluminum stadiometer. The values of lean body mass (LM) and relative body fat (\%BF) were estimated from measurements of the triceps and mid-calf thickness measured on the right side of the body with a Lange ${ }^{\circledR}$ scientific adipometer (Cambridge Scientific Instruments ${ }^{\mathrm{TM}}$, USA), by an experienced evaluator. The \%BF was calculated from specific equations according to the age group (Heyward and Wagner, 2004).

\section{Biological maturation}

The biological maturation (bone age) was determined from radiographs of the left wrist and hand region of each player (Greulich and Pyle, 1959). Participants were grouped into categories of advanced, normal, and delayed maturation based on the difference between bone age (BA) 
and chronological age (CA). The classification criteria used were similar to previous studies (Figueiredo et al., 2009; Malina et al., 2004), whereby: subjects who presented a difference between $\mathrm{BA}$ and $\mathrm{CA}$ within \pm 1 year were classified as normal; subjects with a more advanced bone age relative to their chronological age by more than one year were classified as advanced; and subjects whose bone age was lagging behind their chronological age by more than one year were classified as late.

\section{Motor performance}

Aerobic fitness was measured by the YoYo Intermittent Recovery Level 1 (YYIR1) and the estimated $\mathrm{VO}_{2 \max }$ was calculated for each athlete (Bangsbo et al., 2008).

For the velocity evaluation, a running test with fixed distances of 10 and $30 \mathrm{~m}$ was used (Le Gall et al., 2002). Players began the test from a standing position. The test consisted of running as fast as possible. To record the times of the 10 $(\mathrm{T} 10 \mathrm{~m})$ and $30 \mathrm{~m}(\mathrm{~T} 30 \mathrm{~m})$, a photoelectric cell Multi Sprint ${ }^{\circledR}$ (Hidrofit ${ }^{\mathrm{TM}}$, MG, Brazil) was utilized with a fixed height of approximately 0.6 $\mathrm{m}$. The rest interval between the $710 \mathrm{~m}$ and $730 \mathrm{~m}$ tests was at least 30 minutes, and athletes were allowed two attempts of each test, with a 10-min rest interval between the following attempts. The best result of the two trials was recorded for further analysis.

Three different vertical jumping techniques were followed: maximum vertical jump starting from the semi-squat position, without the aid of the upper limbs (Squat Jump; SJ); maximum vertical jump, with countermovement without the aid of the upper limbs (Countermovement Jump; CMJ); and maximum vertical jump, with countermovement with the aid of the upper limbs (Countermovement Jump Arms; CMJA). For the jump tests, a Multi Sprint ${ }^{\circledR}$ contact mat was used (Hidrofit ${ }^{\mathrm{TM}}$, Brazil). All participants performed three attempts of each type of the jump and the best result was registered for further analysis. The rest interval between each type of the jump was approximately $1 \mathrm{~min}$.

The repeated sprint ability (RSA) test consisted of six sprints of $40 \mathrm{~m}(20 \mathrm{~m}+20 \mathrm{~m}$, shuttle-run) using a Multi Sprint ${ }^{\circledR}$ photocell (Hidrofit ${ }^{\mathrm{TM}}$, Brazil), separated by $20 \mathrm{~s}$ of passive recovery (Impellizzeri et al., 2008). The variables analyzed were the mean sprint time (RSAmean) and the performance drop between the sprints (fatigue index). The fatigue index of RSA (FIRSA) was calculated by dividing the RSAmean by the RSAbest, expressed as a percentage.

The interval between the following testing sessions was $48 \mathrm{~h}$. All the tests were carried out on a soccer field with individuals performing the tests wearing soccer boots and appropriate clothes in order to reproduce as closely as possible the real situation of a practice/game. In addition, participants were instructed not to perform training or any other vigorous physical activity, as well as not to ingest caffeinated substances (coffee, chocolate, mate, guarana power, and coke), or alcoholic substances in the 24 hours before the test to avoid possible interferences.

\section{Statistical Analysis}

Data are presented as means \pm standard deviation (SD). The Gaussian distribution was observed through the Shapiro-Wilk test. The anthropometric data, body composition, and motor performance variables were analyzed using a two-way ANOVA. When significant differences were found, the Scheffé post-hoc test was used. To analyze the distribution of the soccer players according to the birth date every four months and the biological maturational classification, the chisquare test $\left(X^{2}\right)$ was used. The significance level adopted for all analyses was $p \leq 0.05$. Statistical analyses were carried out using SPSS 21.0 software.

\section{Results}

Table 1 shows the distribution of young soccer players in the U-13, U-15, and U-17 age categories, according to the birth tertiles. No significant differences were found between the U$13, \mathrm{U}-15$, and U-17 categories, and birth tertiles $\left(X^{2}\right.$ $=3.42 ; p>0.05$ ).

In relation to anthropometry and body composition, significant differences were observed between the age categories and birth tertiles for the stature, body mass, and lean body mass $(F=10.21, F=9.29$ and $F=9.67$, respectively; $p<0.05$ ) (Table 2). Additionally, it was found that players from the U-13 category presented significantly lower values for the stature, body mass, and lean body mass when compared to players from the U-15 and U-17 categories in the different tertiles $(p<0.05)$ (Table 2). Furthermore, 
there were significant differences between the $1^{\text {st }}$ TR and the $3^{\text {rd }}$ TR for the stature, body mass, and lean body mass of the players of the U-13 and U15 categories $(p<0.05)$ (Table 2$)$. However, there were no significant differences in the relative body fat between the analyzed age categories and birth tertiles $(\mathrm{F}=3.47 ; p>0.05)$ (Table 2$)$.

\section{Table 1}

Absolute (AF) and relative (RF) frequency (\%) values of the distribution of the participants studied in each age category according to the birth tertiles.

\begin{tabular}{cccccccc}
\hline & \multicolumn{2}{c}{ 1 $^{\text {st }}$ TR (Jan-Apr) } & \multicolumn{2}{c}{ 2 $^{\text {nd }}$ TR (May-Aug) } & \multicolumn{2}{c}{ 3 $^{\text {rd }}$ TR (Sept-Dec) } & Total \\
\hline U-13 & AF & RF & AF & RF & AF & RF & \\
U-15 & 16 & $32.0 \%$ & 18 & $36.0 \%$ & 16 & $32.0 \%$ & 50 \\
U-17 & 17 & $34.0 \%$ & 17 & $34.0 \%$ & 16 & $32.0 \%$ & 50 \\
\hline
\end{tabular}

Table 2

Values (mean \pm SD) of anthropometric variables and body composition.

\begin{tabular}{cccc}
\hline \multicolumn{1}{l}{ Variables } & U-13 & U-15 & U-17 \\
\hline Stature $(\mathrm{cm})$ & $165.9 \pm 4.3^{*+}$ & $171.9 \pm 4.9^{+}$ & $176.0 \pm 5.2$ \\
$1^{\circ} \mathrm{TR}$ & $163.6 \pm 4.6^{*}$ & $168.7 \pm 5.0$ & $173.6 \pm 5.1$ \\
$2^{\circ} \mathrm{TR}$ & $161.2 \pm 4.6^{*}$ & $166.9 \pm 4.9$ & $172.1 \pm 5.2$ \\
$3^{\circ} \mathrm{TR}$ & & & \\
Body mass $(\mathrm{kg})$ & $57.5 \pm 3.7^{*+}$ & $61.8 \pm 4.0^{+}$ & $65.4 \pm 3.9$ \\
$1^{\circ} \mathrm{TR}$ & $56.2 \pm 3.5^{*}$ & $60.6 \pm 4.0$ & $64.2 \pm 4.0$ \\
$2^{\circ} \mathrm{TR}$ & $53.7 \pm 3.5^{*}$ & $57.8 \pm 3.9$ & $62.0 \pm 4.2$ \\
$3^{\circ} \mathrm{TR}$ & & & \\
Relative body fat $(\%)$ & $15.3 \pm 2.6$ & $14.4 \pm 2.2$ & $13.4 \pm 3.0$ \\
$1^{\circ} \mathrm{TR}$ & $14.7 \pm 2.5$ & $14.2 \pm 2.3$ & $12.9 \pm 2.7$ \\
$2^{\circ} \mathrm{TR}$ & $14.1 \pm 3.0$ & $13.9 \pm 2.9$ & \\
$3^{\circ} \mathrm{TR}$ & & & $56.3 \pm 3.1$ \\
$1^{\circ} \mathrm{TR}$ & $49.4 \pm 2.8^{*+}$ & $52.8 \pm 2.9^{+}$ & $55.1 \pm 3.1$ \\
$2^{\circ} \mathrm{TR}$ & $48.1 \pm 2.9^{*}$ & $52.2 \pm 3.0$ & $53.2 \pm 3.0$ \\
$3^{\circ} \mathrm{TR}$ & $46.3 \pm 3.0^{*}$ & $50.4 \pm 2.9$ & \\
\hline
\end{tabular}

"Statistically significant differences between the $U-13$ category and the $U-15$ and $U-17$ categories $(p<0.05)$.

+ Statistically significant differences between the $1^{\text {st }}$ and the $3^{\text {rd }}$ TR in the same category $(p<0.05)$. 
Table 3

Absolute (AF) and relative (RF) frequency (\%) values of the biological maturation classification.

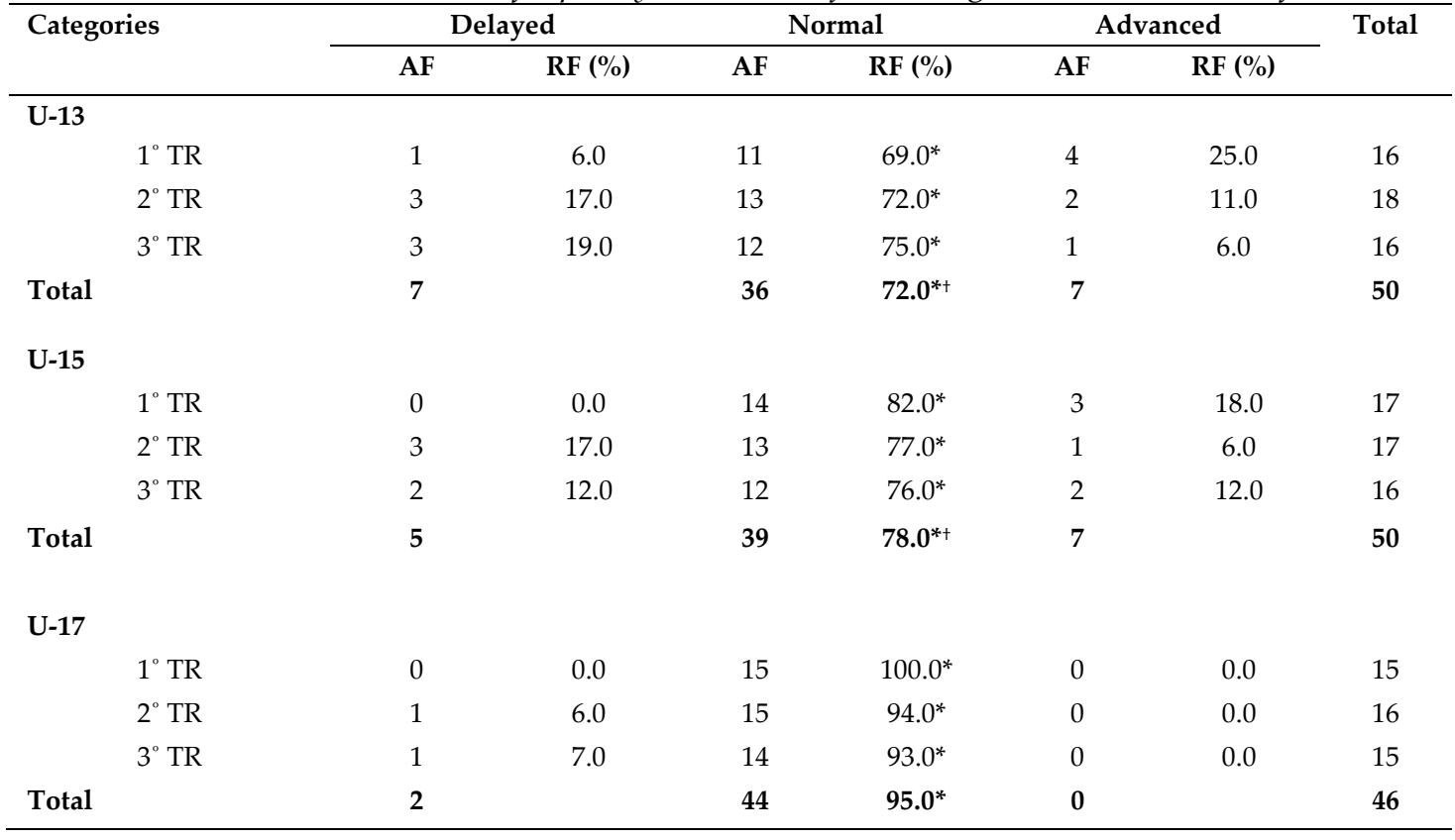

*Statistically significant differences between the classification of the maturational status Normal and the maturational status Delayed and Advanced $(p<0.05)$.

+Statistically significant differences between the $U-13, U-15$, and $U-17$ age categories $(p<0.05)$.

Table 4

Performance (mean \pm SD) in aerobic endurance (YYIR1) and repeated sprint ability (RSA) tests.

\begin{tabular}{lcccc}
\hline \multicolumn{1}{l}{ Variables } & U-13 & U-15 & U-17 \\
\hline YYIR1 $\left(\mathrm{ml} \cdot \mathrm{kg} \cdot \mathrm{min}^{-1}\right)$ & & & \\
& $1^{\circ} \mathrm{TR}$ & $43.1 \pm 3.3^{*}$ & $46.9 \pm 3.9$ & $51.0 \pm 4.0$ \\
& $2^{\circ} \mathrm{TR}$ & $41.9 \pm 3.6^{*}$ & $45.9 \pm 3.8$ & $50.0 \pm 3.7$ \\
& $3^{\circ} \mathrm{TR}$ & $40.4 \pm 4.0^{*}$ & $44.0 \pm 4.9$ & $49.1 \pm 4.2$ \\
RSAmean $(\mathrm{s})$ & & & \\
& & $7.80 \pm 0.25^{*+}$ & $7.38 \pm 0.27^{\dagger}$ & $7.08 \pm 0.27$ \\
& $1^{\circ} \mathrm{TR}$ & $7.92 \pm 0.25^{*}$ & $7.67 \pm 0.28^{\ddagger}$ & $7.16 \pm 0.25$ \\
& $2^{\circ} \mathrm{TR}$ & $8.09 \pm 0.26^{*}$ & $7.79 \pm 0.26^{\ddagger}$ & $7.34 \pm 0.28$ \\
\hline $3^{\circ} \mathrm{TR}$ & ${ }^{*}$ Stati
\end{tabular}

*Statistically significant differences between $U-13$ and $U-17$ categories $(p<0.05)$.

*Statistically significant differences between $U-15$ and $U-17$ categories $(p<0.05)$.

${ }^{+}$Statistically significant differences between the $1^{\text {st }}$ and the $3^{\text {rd }}$ TR in the same category $(p<0.05)$. 

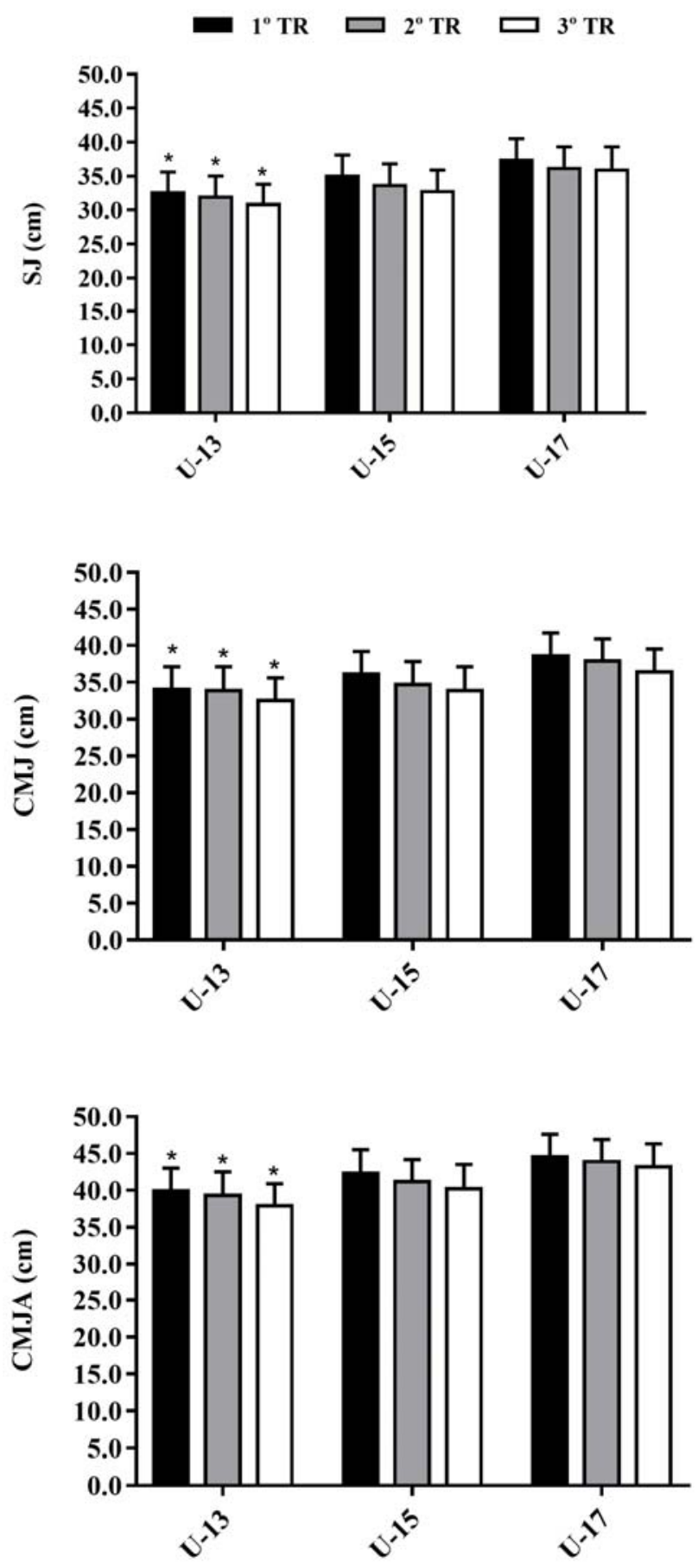

Figure 1

Values (mean $\pm S D$ ) of performance in the tests of evaluation of the power of lower limbs. $S J=$ Squat Jump, $C M J=$ Countermovement Jump, CMJA = Countermovement Jump Arms.

*Statistically significant differences between $U-13$ and $U-17$ categories $(p<0.05)$. 

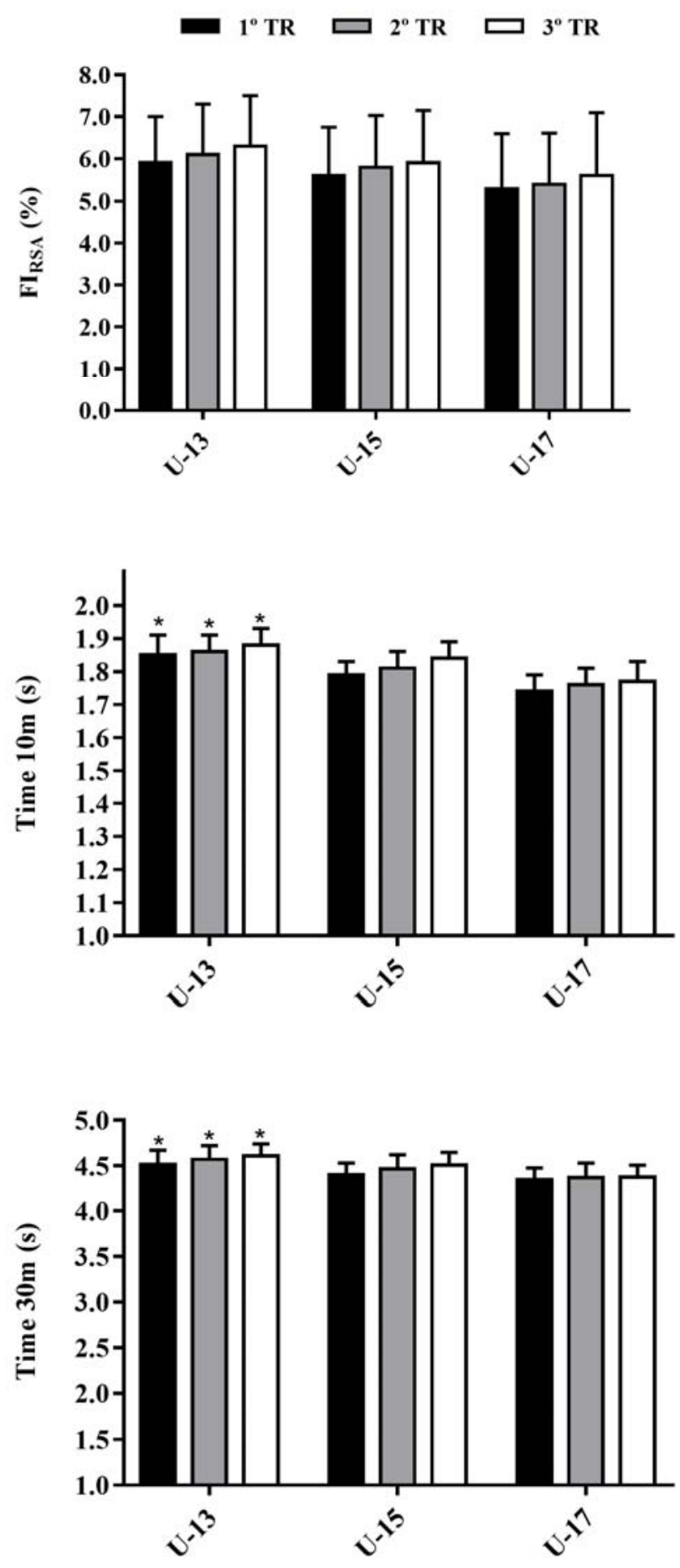

Figure 2

Values (mean $\pm S D$ ) of performance in speed tests of 10 and $30 \mathrm{~m}$ and fatigue index of repeated sprint ability test (FIRSA).

*Statistically significant differences between categories $U-13$ and $U-17(p<0.05)$. 
Table 3 presents the absolute and relative frequency values for the classification of the maturational status of soccer players grouped in the $1^{\text {st }}, 2^{\text {nd }}$, and $3^{\text {rd }}$ TR. Significant differences were observed in maturational status between the age categories, and birth tertiles $\left(X^{2}=30.48 ; p<0.05\right)$. In the three categories analyzed, significant prevalence was observed of soccer players presenting normal maturational status independent of the birth month $(p<0.05)$, being that the U-17 presented higher prevalence than the U-13 and U-15 categories $(95.0 \% ; 72.0$ and $78.0 \%$, respectively; $p<0.05$ ).

Performances in the lower limb power test obtained from the SJ, CMJ, and CMJA tests are shown in Figure 1. No significant differences were found between the birth tertiles for the SJ, CMJ, and CMJA tests $(F=2.37, F=1.98$ and $F=$ 2.00 , respectively; $p>0.05$ ), although a significant difference was observed in age categories in the SJ, CMJ, and CMJA tests $(F=7.12, F=6.58$ and $F=$ 6.95 , respectively; $p<0.05$ ). Players in the U-13 category demonstrated significantly lower values in the SJ, CMJ, and CMJA when compared to the U-15 and U-17 players in different tertiles $(p<$ 0.05).

In relation to aerobic fitness, there was no significant difference in aerobic fitness between the birth tertiles $(F=3.85 ; p>0.05)$, yet a significant difference was observed in age categories $(F=7.81 ; p<0.05)$ (Table 4$)$. Players in the U-13 category presented lower aerobic fitness compared to U-17 players in the different tertiles $(p<0.05)$ (Table 4). In the RSA test, significant differences were found between the age categories and birth tertiles $(F=7.35 ; p<0.05)$ (Table 4$)$. Values in the RSA test were significantly better for U-17 players when compared to U-13 and U-15 players in different tertiles $(p<0.05)$ (Table 4$)$. In addition, significant differences between the $1^{\text {st }}$ and the $3^{\text {rd }}$ TR were observed for players of the U13 and U-15 categories $(p<0.05)$ (Table 4). Furthermore, when analyzing the fatigue index obtained in the RSA test (FIRSA), there were no significant differences between the birth tertiles in all categories analyzed $(F=1.08 ; p>0.05)$ (Figure 2).

Figure 2 shows the data obtained from the speed tests for the U-13, U-15 and U-17 categories, grouped into the $1^{\text {st }}, 2^{\text {nd }}$, and $3^{\text {rd }}$ TR. No significant differences were observed between the birth tertiles for the $710 \mathrm{~m}$ and $730 \mathrm{~m}(F=1.68$ and $F=$ 1.56 , respectively; $p>0.05$ ), although a significant difference in age categories was observed in the $\mathrm{T} 10 \mathrm{~m}$ and $\mathrm{T} 30 \mathrm{~m}(\mathrm{~F}=8.89$ and $\mathrm{F}=10.21$, respectively; $p<0.05)$. U-13 players presented worse values in the $710 \mathrm{~m}$ and $730 \mathrm{~m}$ when compared to U-15 and U-17 players, in all birth tertiles $(p<0.05)$.

\section{Discussion}

The objective of this study was to analyze the influence of the relative age effect (RAE) on anthropometry, body composition, biological maturation, and motor performance in young Brazilian soccer players. The main results of the present study revealed that i) there were differences between age categories and birth tertiles for the stature, body mass, and lean body mass; ii) in the three categories analyzed, significant prevalence of soccer players presenting normal maturational status independent of the birth month was observed; and iii) there was a difference in motor performance between the birth tertiles only for RSA variables, and this difference was observed between age categories.

We did not find any differences in values of the distribution of players in each age category according to the birth tertiles. These results are different from studies that demonstrate higher prevalence of players born in the first tertile of the competitive year in European soccer players from U-15 to U-18 (Helsen et al., 2005), young amateur soccer players and professionals competing in European championships (González-Víllora et al., 2015; Helsen et al., 2012; Williams, 2009). In addition, these results were different from a previous study in our laboratory with the Brazilian soccer teams from U-14 to U-18, who presented a higher number of athletes born in the first four months (Altimari et al., 2011).

The present study verified that the stature, body mass, and lean body mass were different between the $1^{\text {st }}$ and the $3^{\text {rd }}$ TR in the U-13 and U-15 categories $(p<0.05)$. These results corroborate with other studies that demonstrated the influence of the birth date on the anthropometric characteristics of these young players (Altimari et al., 2018; Gil et al., 2014). In addition, anthropometric variables (body mass, stature, and lean body mass) were lower in U-13 players in the different tertiles when compared to 
U-15 and U-17. These results were similar to those from the study of Vaeyens et al. (2006), who demonstrated lower values of anthropometric variables in U-13 players when compared to U-14, $\mathrm{U}-15$, and U-16 players.

Physical growth is a continuous process which occurs over the years, thus individuals born earlier in the year may benefit (months and/or years longer undergoing this growth process) when compared to those born towards the end of the year (Gil et al., 2014), which could explain the results found in this study.

Interestingly, the three categories analyzed in this study showed prevalence of soccer players presenting normal maturity in the three tertiles $(\mathrm{U}-13=72.0 \%$; U-15 $=78.0 \%$; U-17 = $95.0 \%$ ), indicating that influence of the biological maturation may not be determinant for changing physical growth. Similarly, Hirose (2009) found that the stature of young Japanese soccer players born in the final three months of the year was lower than those born in the first trimester, for the U-11, U-13, and U-14 categories, although there was no difference between maturational status and distribution of the birth month in the categories. Perhaps this can be explained by the great biological variability within groups of the same chronological age (Baxter-Jones et al., 2005). Previous studies have shown that soccer players presenting advanced biological maturation are taller, heavier, and demonstrate better motor performance (e.g., running speed, aerobic power, and anaerobic capacity) than normal and delayed athletes (Duarte et al., 2019; Malina et al., 2007; Sherar et al., 2007).

In relation to motor performance, only performance in the RSA test showed significant differences between the first and third tertiles of the U-13 and U-15 players $(p<0.05)$. There were no significant differences between the birth tertiles in other variables. In addition, U-17 players presented better performance in some variables (SJ, CMJ, CMY, YYIR1, RSAmean, T10m, and T30m) compared to U-13 players in the different tertiles $(p<0.05)$.

Although RSA is directly related to performance in soccer (Rampinini et al., 2007), few studies have investigated the RAE on RSA in youth soccer players. In the study of Bliss and Brickley (2011), the influence of RAE on RSA was investigated, and RAE on performance during sprints was observed, although there was no difference in the fatigue index. These findings corroborate our results. However, recently Duarte et al. (2019) observed influence of RAE and predicted maturity status on RSA and the RSA fatigue index in soccer players aged 13-14 years, suggesting that being relatively older and, simultaneously, advanced in maturity status corresponded to a substantial advantage in characteristics related to soccer-specific fitness.

In addition, in the present study, no significant differences were found in performance in the YYIR1 between birth tertiles. This result is in line with the study of Deprez et al. (2012). Moreover, difference in motor performance was found between the age categories, which is similar to the study of Vaeyens et al. (2006). This difference may be explained by the greater muscular mass presented by older players when compared with their younger counterparts, and differences in resynthesis rates of energetic substrates as well as in rates of removal of exercise metabolites (Ratel et al., 2003).

The present study provides interesting data to sports professionals as the results demonstrated that RAE can be detrimental to player selection, because early maturing players (larger body size) are favored in the process of selection (Carling et al., 2009; Duarte et al., 2019; Hirose, 2009; Práxedes et al., 2017). The results indicate that the process based only on anthropometric aspects is a poor indicator of physical performance, and because of this, younger players equally capable (in physical performance) may be underestimated in the selection process due they have lower body size. Therefore, it is extremely important that professionals of sports and health assess players considering several aspects (anthropometry, maturational status and physical performance) during the process of selection, to prevent the loss of talents due to inadequate data.

Finally, the present experiment has some limitations due to the proposed methodology. It was not possible to identify causalities by analyzing associations. In addition, the study did not consider in the analysis the time of practice of young soccer players in the sport, which can be an intervening variable for this type of study. Only male athletes were also investigated, limiting the generalization of findings to female teams. 


\section{Conclusions}

The stature, body mass, lean body mass, and repeated sprint ability in the U-13 and U-15 categories were influenced by the birth date. The other variables were not influenced by months of birth. In addition, U-13 players presented lower values in anthropometric variables and motor performance when compared with players of other categories. Thus, care should be taken during the process of talent selection, as many young players may be underestimated due to their date of birth and consequent inferior morphological attributes.

We suggest new longitudinal studies with monitoring players' training, considering their morphological, physical, maturational, technical and cognitive attributes related to performance in the real game environment, as well as studies that quantify the number of young players, identified as potential talents who have become professional athletes in teams at the high competitive level.

\section{Acknowledgements}

We would like to express thanks to the São Paulo Research Foundation (FAPESP/Brazil, Process:10/09143-0), the Coordination of Improvement of Higher Education Personnel (CAPES/Brazil) and the National Council of Technological and Scientific Development (CNPq/Brazil).

\section{References}

Altimari JM, Altimari LR, Paula L, Bortolotti H, Pasquarelli BN, Ronque ER, Moraes AC. Distribution of soccer players of the Brazilian teams by month of birth. Rev Andal Med Deporte, 2011; 4(1): 13-16

Altimari JM, Bortolotti H, Santos-Junior N, Altimari LR, Moraes AC. Birth month distribution and anthropometric measures of U-15 national elite soccer players. Rev Bras Cineantropometria $\mathcal{E}$ Desempenho Hum, 2018; 20(2): 211-218

Bangsbo J, Iaia FM, Krustrup P. The Yo-Yo intermittent recovery test: a useful tool for evaluation of physical performance in intermittent sports. Sports Med, 2008; 38(1): 37-51

Baxter-Jones ADG, Eisenmann JC, Sherar LB. Controlling for maturation in pediatric exercise science. Pediatr Exerc Sci, 2005; 17(1): 18-30

Bliss A, Brickley G. Effects of relative age on physical and physiological performance characteristics in youth soccer. J Sports Med Phys Fitness, 2011; 51(4): 571-575

Carling C, le Gall F, Reilly T, Williams AM. Do anthropometric and fitness characteristics vary according to birth date distribution in elite youth academy soccer players? Scand J Med Sci Sports, 2009; 19(1): 3-9

Cobley S, Baker J, Wattie N, McKenna J. Annual age-grouping and athlete development: a meta-analytical review of relative age effects in sport. Sports Med, 2009; 39(3): 235-256

Costa ITD, Albuquerque RM, Garganta J. Relative age effect in Brazilian soccer players: a historical analysis. Int J Perform Anal Sport, 2012; 12(3): 563-570

Delorme N, Radel R, Raspaud M. Relative age effect and soccer refereeing: a "strategic adaptation" of relatively younger children? Eur J Sport Sci, 2013; 13(4): 400-406

Deprez D, Vaeyens R., Coutts A, Lenoir M, Philippaerts R. Relative age effect and Yo-Yo IR1 in youth soccer. Int J Sports Med, 2012; 33(12): 987-993

Duarte JP, Coelho-E-Silva MJ, Costa D, Martinho D, Luz LGO, Rebelo-Gonçalves R, Valente-Dos-Santos J, Figueiredo A, Seabra A, Malina RM. Repeated sprint ability in youth soccer players: independent and combined effects of relative age and biological maturity. J Hum Kinet, 2019; 5(67): 209-221

Figueiredo AJ, Gonçalves CE, Coelho e Silva MJ, Malina RM. Youth soccer players, 11-14 years: maturity, size, function, skill and goal orientation. Ann Hum Biol, 2009; 36(1): 60-73

Gil SM, Badiola A, Bidaurrazaga-Letona I, Zabala-Lili J, Gravina L, Santos-Concejero J, Lekue JA, Granados C. Relationship between the relative age effect and anthropometry, maturity and performance in young soccer players. J Sports Sci, 2014; 32(5): 479-486

González-Víllora S, Pastor-Vicedo JC, Cordente D. Relative age effect in UEFA Championship soccer players. J Hum Kinet, 2015; 14(47): 237-248

Gravina L, Gil SM, Ruiz F, Zubero J, Gil J, Irazusta J. Anthropometric and physiological differences between 
first team and reserve soccer players aged 10-14 years at the beginning and end of the season. $J$ Strength Cond Res, 2008; 22(4): 1308-1314

Greulich WW, Pyle SI. Radiographic atlas of skeletal development of the hand and wrist. Stanford: Calif; 1959

Helsen WF, Baker J, Michiels S, Schorer J, Van winckel J, Williams AM. The relative age effect in European professional soccer: did ten years of research make any difference? J Sports Sci, 2012; 30(15): 1665-1671

Helsen WF, van Winckel J, Williams AM. The relative age effect in youth soccer across Europe. J Sports Sci, 2005; 23(6): 629-636

Heyward VH, Wagner DR. Applied body composition assessment. Champaign: Human Kinetics; 2004.

Hirose N. Relationships among birth-month distribution, skeletal age and anthropometric characteristics in adolescent elite soccer players. J Sports Sci, 2009; 27(11): 1159-1166

Impellizzeri F, Rampinini E, Castagna C, Bishop D, Ferrari Bravo D, Tibaudi A, Wisloff U. Validity of a repeated-sprint test for football. Int J Sports Med, 2008; 29(11): 899-905

Le Gall F, Beillot J, Rochcongar P. The improvement in maximal anaerobic power of soccer players during growth. Sci Sports, 2002; 17(4): 177-188

López de Subijana C, Lorenzo J. Relative age effect and long-term success in the Spanish soccer and basketball national teams. J Hum Kinet, 2018; 31(65): 197-204

Malina RM, Chamorro M, Serratosa L, Morate F. TW3 and Fels skeletal ages in elite youth soccer players. Ann Hum Biol, 2007; 34(2): 265-272

Malina RM, Eisenmann JC, Cumming SP, Ribeiro B, Aroso J. Maturity-associated variation in the growth and functional capacities of youth football (soccer) players 13-15 years. Eur J Appl Physiol, 2004; 91(5-6): $555-562$

Musch J, Grondin S. Unequal competition as an impediment to personal development: a review of the relative age effect in sport. Dev Rev, 2001; 21(2): 147-167

Práxedes A, Moreno A, García-González L, Pizarro D, Del Villar F. The relative age effect on soccer players in formative stages with different sport expertise levels. J Hum Kinet, 2017; 28(60): 167-173

Rampinini E, Bishop D, Marcora S, Ferrari Bravo D, Sassi R, Impellizzeri F. Validity of simple field tests as indicators of match-related physical performance in top-level professional soccer players. Int J Sports Med, 2007; 28(3): 228-235

Ratel S, Lazaar N, Williams CA, Bedu M, Duché P. Age differences in human skeletal muscle fatigue during high-intensity intermittent exercise. Acta Paediatr, 2003; 92(11): 1248-1254

Sedano S, Vaeyens R, Redondo JC. The Relative age effect in Spanish female soccer players influence of the competitive level and a playing position. J Hum Kinet, 2015; 10(46): 129-137

Sherar LB, Baxter-Jones ADG, Faulkner RA, Russell KW. Do physical maturity and birth date predict talent in male youth ice hockey players? J Sports Sci, 2007; 25(8): 879-886

Vaeyens R, Malina RM, Janssens M, Van Renterghem B, Bourgois J, Vrijens J, Philippaerts RM, Silva MJC. A multidisciplinary selection model for youth soccer: the Ghent Youth Soccer Project. Br J Sports Med, 2006; 40(11): 928-934

Vincent J, Glamser FD. Gender differences in the relative age effect among US Olympic development program youth soccer players. J Sports Sci, 2006; 24(4): 405-413

Williams JH. Relative age effect in youth soccer: analysis of the FIFA U17 World Cup competition: Age effect in youth soccer. Scand J Med Sci Sports, 2009; 20(3): 502-508

Wong PL, Chamari K, Dellal A, Wisløff U. Relationship between anthropometric and physiological characteristics in youth soccer players. J Strength Cond Res, 2009; 23(4): 1204-1210

Wrang CM, Rossing NN, Diernæs RM, Hansen CG, Dalgaard-Hansen C, Karbing DS. Relative age effect and the re-selection of Danish male handball players for national teams. J Hum Kinet, 2018; 24(63): 33-41

\section{Corresponding author:}

\section{Juliana Melo Altimari}

Group of Study and Research in Neuromuscular System and Exercise, Physical Education and Sport Center State University of Londrina. Road Celso Garcia Cid, PR 445 Km 380, ZIP Code 86051-990, Londrina, PR, Brazil. Phone: +55 4399127 0536;

Email: altimari@uel.br 